\title{
Prediction Model of Milling Surface Roughness Based on Regression Analysis
}

\author{
Ying Chen ${ }^{\mathrm{a}^{*}}$, Yanhong Sun ${ }^{\mathrm{b}}$, Han Lin $^{\mathrm{c}}$ and Bing Zhang ${ }^{\mathrm{d}}$ \\ College of Mechanical Engineering, Jilin Engineering Normal University, \\ Changchun 130052, China

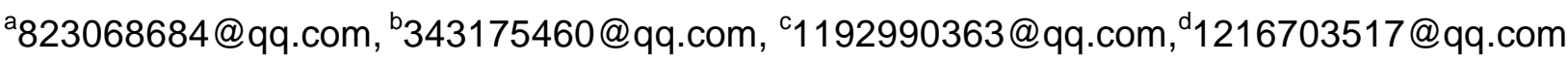 \\ * The Corresponding Author
}

Keywords: Surface roughness; High speed milling; Multiple regression analysis; Prediction model

\begin{abstract}
Based on the orthogonal test results, a prediction model for surface roughness of high-speed milling work-piece with ring cutter is established by regression analysis method, the regression equation and coefficient of the model are tested for significance. The model is highly significant for the prediction of surface roughness. The effect of milling amount on the surface roughness is studied through the analysis of the orthogonal test intuitionistic diagram. It provides a reliable basis for the rational selection of milling parameters.
\end{abstract}

\section{Introduction}

In NC machining, surface roughness is one of the important indexes for parts design and measurement of surface quality. Roughness affects the wear resistance, corrosion resistance and fatigue resistance of parts directly, and also affects the accuracy and quality of assembly. Because of the high speed cutting mechanism of surface roughness formation is not mature, there are many factors influencing the high-speed cutting surface roughness, the coupling between each other. Therefore, the influence of machining parameters on surface quality should be analyzed through cutting experiments, and the surface roughness model is established, which provides a reliable basis for reasonable selection of milling parameters.

\section{Test Conditions for Cutting}

On the DMU125P five axis milling machine, P1.2738 plastic die steel was cut by ring milling cutter with a diameter of $25 \mathrm{~mm}$, and oil mist cooling was applied. The surface roughness was measured by the surface roughness tester. The test results of each group were measured for 10 times, and the mean value was taken as the measurement result.

The orthogonal test method to test the number of main contradiction may be less exhausted by the orthogonal table to find the influencing factors of the comprehensive comparison and statistical analysis, this test mainly aims at cutting parameters : cutting speed(spindle speed), feed rate and milling depth, the radial feed, tool diameter and other conditions in the premise as the known conditions of the surface roughness, using four factors and four levels orthogonal table (second column empty column) based tab. Table 1 shows the level of each factor, and the result of the test is listed in table 2.

\section{The Establishment of the Prediction Model of Surface Roughness.}

In high speed end milling, cutting parameters mainly include cutting speed (or spindle speed), feed speed, axial cutting depth and radial cutting depth. On the premise of determining the characteristics of the machine tool and the geometric parameters of the tool, the exponential relation between the surface roughness and the cutting amount is established by the orthogonal regression test.

$$
R a=K a_{p}^{b_{1}} n^{b_{3}} f_{z}^{b_{3}} a_{e}^{b_{4}}
$$

Here, $K-$ Correction factor determined by the processing material 
$b_{1}, b_{2}, b_{3}, b_{4}-$ The index of each cutting amount

Table 1 Level of four factor and four level test factor

\begin{tabular}{ccccc}
\hline & \multicolumn{4}{c}{ test factor } \\
\cline { 2 - 5 } level & $\begin{array}{c}\text { Milling } \\
\text { depth } \\
a_{p}[\mathrm{~mm}]\end{array}$ & $\begin{array}{c}\text { Spindle } \\
\text { speed } \\
n[\mathrm{r} / \mathrm{min}]\end{array}$ & $\begin{array}{c}\text { Feed per } \\
\text { tooth } \\
f_{z}[\mathrm{~mm} / \mathrm{r}]\end{array}$ & $\begin{array}{c}\text { Milling } \\
\text { spacing } \\
a_{e}[\mathrm{~mm}]\end{array}$ \\
\hline 1 & 0.05 & 6000 & 0.05 & 2 \\
2 & 0.10 & 6500 & 0.10 & 4 \\
3 & 0.15 & 7000 & 0.15 & 6 \\
4 & 0.20 & 7500 & 0.20 & 8 \\
\hline
\end{tabular}

Table 2 Orthogonal experimental design $L_{16}\left(4^{5}\right)$

\begin{tabular}{cccccc}
\hline No. & $\begin{array}{c}\text { Milling } \\
\text { depth } \\
a_{p}[\mathrm{~mm}]\end{array}$ & $\begin{array}{c}\text { Spindle } \\
\text { speed } \\
n[r / \mathrm{min}]\end{array}$ & $\begin{array}{c}\text { Feed per } \\
\text { tooth } \\
f_{z}[\mathrm{~mm} / r]\end{array}$ & $\begin{array}{c}\text { Milling } \\
\text { spacing } \\
a_{e}[\mathrm{~mm}]\end{array}$ & $\begin{array}{c}\text { surface } \\
\text { roughness } \\
\mathrm{Ra}(\text { um })\end{array}$ \\
\hline 1 & 0.05 & 6000 & 0.05 & 2 & 0.434 \\
2 & 0.05 & 6500 & 0.10 & 4 & 0.536 \\
3 & 0.05 & 7000 & 0.15 & 6 & 0.599 \\
4 & 0.05 & 7500 & 0.20 & 8 & 0.682 \\
5 & 0.10 & 6500 & 0.15 & 8 & 0.664 \\
6 & 0.10 & 6000 & 0.20 & 6 & 0.743 \\
7 & 0.10 & 7500 & 0.05 & 4 & 0.389 \\
8 & 0.10 & 7000 & 0.10 & 2 & 0.378 \\
9 & 0.15 & 7000 & 0.20 & 4 & 0.654 \\
10 & 0.15 & 7500 & 0.15 & 2 & 0.610 \\
11 & 0.15 & 6000 & 0.10 & 8 & 0.631 \\
12 & 0.15 & 6500 & 0.05 & 6 & 0.434 \\
13 & 0.20 & 7500 & 0.10 & 6 & 0.723 \\
14 & 0.20 & 7000 & 0.05 & 8 & 0.535 \\
15 & 0.20 & 6500 & 0.20 & 2 & 0.555 \\
16 & 0.20 & 6000 & 0.15 & 4 & 0.667 \\
\hline
\end{tabular}

Since the upper form is a nonlinear function, the logarithms of the upper two sides are taken at the same time so that they can be converted into linear functions. The simplification is as follows

$$
\lg R a=\lg K+b_{1} \lg a_{p}+b_{2} \lg n+b_{3} \lg f_{z}+b_{4} \lg a_{e}
$$

Let $y=\lg R a, x_{1}=\lg a_{p}, x_{2}=\lg n, x_{3}=\lg f_{z}, x_{4}=\lg a_{e}, b_{0}=\lg K$, The Eq.2 is simplified as

$$
y=b_{0}+b_{1} x_{1}+b_{2} x_{2}+b_{3} x_{3}+b_{4} x_{4}
$$

The linear equation consists of four independent variables $x_{1}, x_{2}, x_{3}, x_{4}$, and the results of the test is $y$. In order to determine the specific value coefficient of $b_{0}, b_{1}, b_{2}, b_{3}, b_{4}, 16$ sets of experiments are contained using four factors and four levels of income, the corresponding variables of the i-st group test recorded as $x_{i 1}, x_{i 2}, x_{i 3}, x_{i 4}$, the test results recorded as $y_{i}$, from 16 sets of test data with random variable error $\varepsilon$ in the test can establish multiple linear regression equation: 


$$
\begin{aligned}
& \left\{\begin{array}{c}
y_{1}=\beta_{0}+\beta_{1} x_{11}+\beta_{2} x_{12}+\beta_{3} x_{13}+\beta_{4} x_{14}+\varepsilon_{1} \\
y_{2}=\beta_{0}+\beta_{1} x_{21}+\beta_{2} x_{22}+\beta_{3} x_{13}+\beta_{4} x_{14}+\varepsilon_{2} \\
\vdots \quad \vdots \quad \vdots \quad \vdots \quad \vdots \quad \vdots \quad \vdots \quad \vdots \\
y_{16}=\beta_{0}+\beta_{1} x_{161}+\beta_{2} x_{162}+\beta_{3} x_{163}+\beta_{4} x_{164}+\varepsilon_{16}
\end{array}\right. \\
& Y=\left[\begin{array}{c}
y_{1} \\
y_{2} \\
\vdots \\
y_{16}
\end{array}\right] \beta=\left[\begin{array}{c}
\beta_{0} \\
\beta_{1} \\
\vdots \\
\beta_{4}
\end{array}\right] \varepsilon=\left[\begin{array}{c}
\varepsilon_{1} \\
\varepsilon_{2} \\
\vdots \\
\varepsilon_{16}
\end{array}\right] \mathrm{X}=\left[\begin{array}{lllll}
1 & x_{11} & x_{12} & x_{13} & x_{14} \\
1 & x_{21} & x_{22} & x_{23} & x_{24} \\
\vdots & \vdots & \vdots & \vdots & \vdots \\
1 & x_{161} & x_{162} & x_{163} & x_{164}
\end{array}\right]
\end{aligned}
$$

Finishing type of Eq.4 :

$$
Y=X \beta+\varepsilon
$$

The least square estimation $b_{0}, b_{1}, b_{2}, b_{3}, b_{4}$, of the parameters $\beta_{0}, \beta_{1}, \beta_{2}, \beta_{3}, \beta_{4}$ is set, respectively. The regression equation to determine the parameters is as follows:

$$
\hat{y}=b_{0}+b_{1} x_{1}+b_{2} x_{2}+b_{3} x_{3}+b_{4} x_{4}
$$

In Eq.6, $\hat{y}$ is the statistical variable and $b_{0}, b_{1}, b_{2}, b_{3}, b_{4}$ is the regression coefficient, it can be calculated by calculation.

$$
b=\left(X^{\prime} X\right)^{-1} X^{\prime} Y
$$

\section{The Establishment of Empirical Formula}

In order to transform the model into a linear model, it is easy to establish prediction models for mathematical regression analysis. The natural logarithms of the test data tables can be obtained according to Eq.4 Eq.7.



The predictive regression equation based on the experimental data can be obtained by Eq.8.

$$
\hat{y}=0.7279+0.0720 x_{1}-0.1967 x_{2}+0.2903 x_{3}+0.1912 x_{4}
$$

As a result, the calculation formula of the surface roughness value of the plastic die steel P1.2738 work-piece by using the milling cutter is as follows:

$$
R a=10^{0.7279} a_{p}^{0.0720} n^{-0.2449} f_{z}^{0.2903} a_{e}^{0.1912}=7.9524 a_{p}^{0.0720} n^{-0.1967} f_{z}^{0.2903} a^{0.1912}
$$

\section{The Significance Test of the Surface Roughness Model}

The Saliency Test of the Regression Equation. In order to evaluate the fitting degree of the surface roughness prediction model, we need to make a significant test on this assumption. We usually decompose the sum of the total $S_{T}$ deviations squared into the two parts : the sum of squares $S_{A}$ and the sum of squares $S_{E}$. It is assumed $b_{\mathrm{i}}=0(i=1,2,3,4)$ that the statistics of the F test method are as follows:

$$
F=\frac{S_{A} / p}{S_{E} /(n-p-1)} \sim F(p, n-p-1)
$$

The number of the test groups is $n, n=16$; the number of variables is $p, p=4$. The calculation results are listed in table 3 . 
Table 3 Regression analysis of variance

\begin{tabular}{lllll}
\hline $\begin{array}{l}\text { Source of } \\
\text { variance }\end{array}$ & $\begin{array}{l}\text { Sum of } \\
\text { squares }\end{array}$ & Freedom & $\begin{array}{l}\text { mean } \\
\text { square }\end{array}$ & Ratio of F \\
\hline regression $S_{A}$ & 0.2107 & 4 & 0.0527 & \\
Surplus $S_{E}$ & 0.0444 & 11 & 0.0040 & $13.175>3.36$ \\
Total $S_{T}$ & 0.2552 & 15 & & \\
\hline
\end{tabular}

When the test level is $\alpha=0.05, F(4,11)=3.36$, because $13.175>3.36$, the prediction model of the surface roughness value when the milling cutter is milling the surface is highly significant.

The Significance Test of Regression Coefficient. Regression test can verify the significance of regression equation. In order to investigate the influence of every independent variable on dependent variable, we need to test the significance of regression coefficient.

The application of the $\mathrm{F}$ test method, assuming $b_{i}=0(i=1,2,3,4)$ that the statistics can be calculated in a pressing way:

$$
F=\frac{b_{i}^{2} / c_{i i}}{S_{E} /(n-p-1)} \sim F(1, n-p-1)
$$

The number of the experimental groups is $n$; the number of the independent variables is $p$; $c_{i i}$ is the element on the diagonal in the correlation matrix $c=\left(X^{\prime} X\right)^{-1}$.

According to Eq.10, we know that: $F_{l}=1.0504\left(a_{p}\right) ; F_{2}=0.2001(n) ; F_{3}=17.0801\left(f_{z}\right) ; F_{4}=7.4098\left(a_{e}\right)$

When the test level is $\alpha=0.05, F(1,11)=4.84$, because 17.0801 and 7.4098 are more than 3.23 , the effect of the milling cutter on the surface roughness $F_{3}, F_{4}$ is highly significant. Through the above analysis, the plastic mold steel P1.2738, which was ranked as: feed speed $f_{z}>$ spaced axial $a_{e}>$ cutting depth $a_{p}>$ cutting spindle speed $n$, spindle speed and cutting line spacing influence is consistent with the results obtained in the range of the law, the order of the other two factors influence is relatively small and slightly different in this method, it is also affected by other factors.

\section{Conclusion}

The prediction model of surface roughness is get through analyzing of the orthogonal test results. The regression equation and the coefficients were significant test. The results showed that the regression equation of surface roughness formula is significant; the surface roughness empirical formula can be achieved on the prediction of surface roughness, and provide the basis for the optimization of cutting parameters.

\section{References}

[1] Su-Yu Wang, Xing-Ai, Jun Zhao And Zeng-Wen Liu: Technology And Test, 2006 , No.8,P.65.

[2] J.S.Yang, H.W.Guo And J.S. Yang: Mechanical Manufacturing And Research,2011,40 (3), 34-35,P.104.

[3] Xin-Li Tian, An-Ying She: Technology And Test, 2008, No.11,P.101

[4] Li-Xin Cao, Hu Gong, Jian Liu: Journal Of Materials Processing Technology, 2007, 184,P.6.

[5] N.Baskar, P.Asokan,R, Saravanan: Int J Adv Manuf Technol 2005(26),P.1202.

[6] W. Wang, S. Tang And Y. Y. Zhang: Mechanical Design And Manufacturing,2010 No.3,P.216. 